\title{
الممارسات الدينية ونقد العقلانية
}

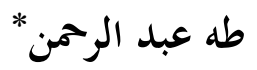

كثر الخوض في موضوع (العقلانية)، حتى تواردت عليه ضروب من الشبهة والإشكال، وتطرقت إليه صنوف

من الخلل والفساد، هذه الضروب والصنوف التي نحتاج إلى استجلاء أوصافها، وبيان أسبابها وتحديد آثارها، حتى نحتز من الوقوع فيها، ونتخير طريقاً سليماً في العقلانية كون موافقاً للممارسة الدينية الإسلامية.

ننطل في هذا العرض التقويمي للعقلانية من واقع الاشتغال بها، فنقول بأن من يتأمل هذا الواقع يتبين فيه الحقائق الثلاث الآتية: - n

الأولى: الدعوة إلى التزام العقلانية، فإن كل من تولّى النظر في وسائل النهوض بواقع العالم الإسلامي والعربي، لم يتردد في أن ينصبّ العقلانية مثالاً لوسائل النهضة، وإماماً للناس يُهتدى به، كما لم يتردد في أن يدخل في الإشادة لئل بفضائل المناهج العقلية وفوائدها في تحصيل المطلوب من التقدم والتحضر.

الثانية: تعار المبادئ العقدية للداعين إلى العقلانية، فإن التعلق بالعقلانية تساوى فيه من تُوَِّهُهُ مبادئ الدين الإسلامي، ومن يميل عن هذا الدين مبتغياً العمل بمبادئ أخرى، أو من ينزل بمنزلة بين هذين الطرفين منتقياً بعض المبادئ من الدين الإسلامي. والبعض الآخر من مذاهب غير إسلامية أو غير دينية، بحجة مسايرة التطور والاستجابة لمقتضى التغيير.

الثالثة: امتداد الدعوة إلى العقلانية، فإن هذه الدعوة إلى العقلانية التي تلوي بها مختلف الفئات الإسلامية والعربية ألسنتها، تزايدت في الشدة والانتشار على مدى فترة استغرقت قرناً ونصف القرن من الزمن، وامتدت من منتصف القرن التاسع عشر إلى فاية القرن العشرين. 
إن هذه الحقائق الثلاث: "الدعوة إلى التزام العقلانية" و "تعارض المبادئ العقدية للداعين إليها" و "امتداد هذه الدعوة مع مرور الزمن"، كان من شأها أن تستوقف المفكر الإسلامي، وتحمله على إجراء تمحيص لذذه العقلانية في خختلف مبادئها ومناهجها وقيمها، حتى يتبين مدى وفائها بالأهداف الإصلاحية والتغيرية التي علقت عليها واستعملت لأجلها وحدود هذا الوفاء، لكن ظل هؤلاء المفكرون في غفلة تامة عن ضرورة هذا التمحيص، وأبوا إلا التمادي في التعلّق بالعقلانية، في الاحتجاج بها والاحتكام إليها، لاعتقادهم الراسخ في كمال مبادئها وبتحس مناهجها، وسلامة مآلاتما، حتى إفم لو فوتوا في أمر هذا التمحيص، وأشعروا باستعجال الحاجة إليه، لكرهوا الدخول فيه، لما بلغه هذا الاعتقاد من أنفسهم.

وتداركاً لذذا النقص، وطلباً للخروج من هذه الغفلة، ندبنا أنفسنا للقيام بعملية النقد المطلوب للعقلانية، لاسيما وأن الاقتناع حاصل عندنا أنه لا يتصور أن يجتمع على معنى واحد للعقلانية من دخل في العمل الشرعي ومن أبى الدخول فيه، كما أن الاقتناع حاصل عندنا بأن عدم التحقق من الوجه الذي تدل به العقلانية عند التارك للعمل الشرعي من شانه أن يوقع الداخل فيه في الأخذ، من حيث لا يشعر بطرق في العقلانية تضر بعمله، وذلك لغلبة الطرق العقلانية المبنية في غياب العمل الشرعي، داخل الممارسة الفكرية والعلمية بوجه عام.

\section{تقويم العقلانية الجزردة:}

حقاً، لقد تعددت تعاري العقل، واختلفت حدود العقلانية وأوصافها، كما تنوعت الآراء فيها بتنوع مستويات أصحابها من الوعي والتحصيل، وتلونت مواقفهم منها بتلون اختياراتم المذهبية وانتماءاتم الفكرية.

ولا نبتغي هنا جرد هذه التعاريف، ومقارنة هذه الآراء والمواقف، بقدر ما هدف إلى وضع معايير عامة يجب أن يستوفيها كل تعريف للعقلانية.

فلتحديد العقلانية معايير، وهذه المعايير التي ينبغي أن ينضبط بها كل تعريف للعقلانية، نصرها في ثلاثة. المعيار الأول هو معيار الفاعلية، ومقتضاه أن الإنسان يتحقق بواسطة أفعاله. ويظهر تحقق الإنسان بواسطة الأفعال، فيما يتطلبه ويتخذه من يختلف المواقف التي تتجدد بمجموعها طبيعة سلوكه. 
والمعيار الثاني هو معيار القيمية، ومقتضاه أن الإنسان لا يركن إلى ماهو كائن وماهو واقع، بل يسعى دوماً أن يكون موجهاً بقيم معينة تُملي عليه ما يجب أن يكون وما يجب أن يقع، ومشدوداً إلى مفاهيم تعلو بكمته إلى الخروج عن حالة الحاضر، وابتغاء أحوال أفضل منها، ولا أدل على ذلك من كونه يطلب الكمال في كل أفعاله، فلا يصل إلى تلى مرتبة حتى يطلب مرتبة فوقها، ولا يزال آخذاً في هذا التدرج من كامل إلى أكمل منه فالأكمل، ولولا هذا التعلق بما ينبغي أن يكون لما خرج الإنسان إلى طلب الكمال، واستفرغ الجهد في تحصيله.

أما المعيار الثالث هو معيار التكاملية، ومقتضاه أن الإنسان على اختلاف مظاهره، وتعدد قدراته ووظائف أعضائه، ليس بجموعة من الجزاء التي تقبل إيقاع الانفصال بينها، وإيقاف التأثير بعضها في بعض، وإنما هو عبارة عن ذات واحدة بتحمع فيها مظاهر القوة مع مظاهر الضعف، كما بتمع فيها صفات العرفان مع صفات الوجدان، ومستويات النظر مع مستويات العمل، وقيم الجسم مع قيم الروح.

بعد توضيحنا للمعايير الثلاثة الواجبة في كل تعريف للعقلانية وهي: "معيار الفاعلية" الذي يقول بتحقيق الإنسان عن طريق الأفعال، و"معيار القيمية" الذي يقضي بأن تستند هذه الأفعال إلى قيم معينة، و"معيار التكامل" الذي يجعل هذه الأفعال الموجهة متضافرة فيما بينها ومكمل بعضها للبعض الآخر، ننعطف على تقويم تعريفين اثنين للعقلانية، أحدهما قديم كان له بالغ الأثر في التراث الإسلامي، وثانيهما حديث لا يقل أثراً في الخطاب الإسلامي والعربي المعاصر.

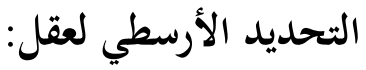

أمل التعريف الأول، فهو التعريف اليوناني الأرسطي، الذي يجعل من العقل جوهراً قائماً بالإنسان يفارق به الحيوان، ويستعد به لقبول المعرفة،. لو عرضنا هذا التعريف على المعايير سالفة الذكر، لتبين لنا أنه لايوفن متقضى معيار الفاعلية، ولا بمقتضى معيار التكاملية وأن وفّ في حدود، بمعيار القيمية. أما من حيث معيار الفاعلية، فها التعريف يجعل من العقل جوهراً، أي شيئاً ينزل منزلة الذات، بينما الصواب أن يكون العقل فعلاً من الأفعال وسلوكاً من السلوكيات، بل أن يكون أدل الأفعال على الفاعلية وعلى أوصافها، 
وبيان ذلك من وجوه ثلاثة، الوجه الأول دخول العقل في جميع الأفعال الإنسانية، فالناظر ينظر وهو يعقل في نظره والسامع يسمع وهو يعقل في سمعه، والعامل يعمل وهو يعقل في عمله. والوجه الثاني أن العقل قد يُحسن ويقبّح كما تحسّن وتقبّح الأفعال، فيحسّن إذا سلك به صاحبه مسالك المعرفة الحقيقية، ويُعتبّح إذا انخرف به عن جادة المعرفة، وأوقعه في المظان والشبهات والأهواء. أما الوجه الثالث فهو أن العقل يقبل التحوّل والتغير كما تقبلهما الأفعال، فبالإمكان توجيه الفعل العقلي والتأثير فيه، بحيث يخرج من وصف عقلي إلى وصف عقلي آخر أفضل وأعقل منه.وأما من حيث معيار التكاملية، فإن هذا التعريف يقسم الإنسان إلى أقسام مستقلة ومتباينة، ذلك أن تخصيص العقل بصفة الذات، يجعله منفصلاً عن أوصاف أخرى للعاقل، تشارك في تحديد ماهية الإنسان كالعمل والتجربة، فلو جاز التسليم بجوهرية العقل على طريقة اليونان، لجاز التسليم بجوهرية العمل وجوهرية التجربة، فيكون العمل هو الآخر ذاتاً قائمة بالإنسان، كما تكون التجربة جوهراً مفارقاً، مثله مثل جوهر العقل، ولا يخفى ما في القول بتعدد الذوات القائمة في الإنسان: "ذات عاقلة" و"ذات عاملة" و"ذات مجربة" من مجانبة للصواب لأنه يتجاهل حقيقة وحدة الإنسان في تكامل أوصافه وتداخل أفعاله.

وأما معيار القيمية، وإن كنا نسلم بأن التعريف الأرسطي للعقلانية يوفي بحقه، فإن هذه التوفيه ضلت الطريق، حيث إن القسيم التي وقع طلبها والتوجه إليها، لا تؤمن عواقبها وتنقلب بأشد الضرر على صاحبها، ولا أدل على ذلك من القول "بالعقول العشرة"، وإنزالها منزلة الآلهة.

فالتصور اليوناني للعقلانية يخل بمعيار الفاعلية، ومعيار التكاملية الضروريين في كل تعريف لها مع إساءة استعمال معيار القيمية.

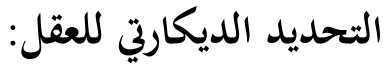

أما التعريف الثاني الذي نريد النظر فيه، فهو التعريف الديكارتي الذي يجعل العقلانية قائمة في معنى استخدام المنهج العقلي، كما يتحدد في سياق ممارسة العلوم الحديثة، وحتى يتسنى لنا الحكم على هذا التصور الحديث للعقلانية، نحتاج إلى مزيد من تفصيل المعايير الثلاثة التي ذكرناها ببيان بعض النتائج المترتبة عليها. 
فمعيار القيمية المذكور، يترتب عليه أن الإنسان لا يفتأ يحدد أهدافاً وغايات (أو بالإصلاح الأصولي "مقاصد"

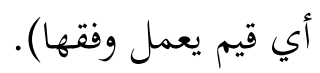

ومعلوم أن هذه المقاصد تتصف بالتنّّع، فمنها الأصلي والفرعي، ومها الأصيل والدخيل، ومنها الموروث والمكتسب. ويمكن تقسيمها إلى قسمين: قسم المقاصد النافعة، وقسم المقاصد غير النافعة أو الضارة. أما معيار الفاعلية السابق، فيترتب عليه أن الإنسان يتخذ الأفعال لبلوغ هذه المقاصد. ومعلوم أن هذه الوسائل تتصف هي الأخرى بالتعدد وقد تتعدد بالنسبة للمقصد الواحد. ويمكن تصنيفها هي الأخرى إلى صنفين هما: صنف الوسائل الناجعة، وصنف الوسائل غير الناجعة.

وأما معيار التكاملية السالف، فيلزم عنه أن تكون الوسائل، والمقاصد خادمة لوحدة مظاهر الإنسان، ولايمكن أن تكون خادمة لهذه الواحدة، إلا إذا اتصفت الوسائل بوصف النجاعة.

وإذا تبين أن معيار القيمية يتعلق بالمقاصد، وأن معيار الفاعلية يتعلق بالوسائل، وان معيار التكاملية يتعلق بالنفع في المقاصد والنجاعة في الوسائل، حق لنا أن نتساءل هل يستجيب المنهج العقلي ذو الأصل الديكارتي، لشرط النفع في المقاصد ولشرط النجاعة في الوسائل.

\section{المنهج العقلي العلمي وحدود النقع في المقاصد:}

إن الناظر في مقاصد هذا المنهج العقلي العلمي، يتبين له أها تتصف بأوصاف ثلاثة: أولها النسبية، فإذا كان من المقاصد النافعة، أن تكون قوانين العقل مشتركة وكلية وواحدة عند كل عاقل وكل ناظر، فإن واقع هذا العلم يشهد غير ذلك، فالمنطق الذي يشتغل بدراسة قوانين العقل، يبدو مشتملاً على صنوف متكاثرة ومتغيرة، من القواعد والمسلمات ومن الأنساق التي تبنى عليها. فضلاً عن الاختلاف المشهور في العلوم الرياضية مثال: (الهندسة الإقليدية واللاإقليدية)، والعلوم الفيزيائية مثال: (نظرية المكان المطلق ونظرية النسبية). 
ولما كانت طرق العلوم بمثل هذا التنكاثر والاختلاف، فإن إنشاء خطاب علمي عن العقل الإنساني، بوصفه حقيقة واحدة مشتركة بين الناس، لايمكن اعتباره مقصداً من المقاصد التي يتوخاها المنهج العقلي العلمي. والوصف الثاني هو الاسترقاقية، فإذا كان من المقاصد النافعة أيضاً، أن تؤدي المناهج العلمية إلى تحرير الإنسان، وتوسيع إمكانات وآفاق إسعاده وآفاق هذا الإسعاد، فإن إمعان النظر في الأحوال التي تنقلب فيها المناهج التقنية، تظهر لنا أن هذه الآمال الواهية بعيدة كل البعد عن التحقق، والسبب في ذلك أن هذه التقنيات توالدت وتكاثرت على جميع المستويات ويز كل الاتحاهات، مشكلةً كوناً تقنياً خاصاً يحتوي الإنسان احتواءً، ويستحوذُ على لى إرادته وتغيب آفاقه عن عقله، بعد أن كان هذا الإنسان يمُنّي النفس بان يسخر الكون له تسخيراً. وما هذا الانقلاب على الإنسان إلا لأن التقنيات أخذت تستقل بنفسها، وتسير وفق منطلقها الخاص بغير بصيرة من الإنسان، وقوام هذا المنطق الآلي مبدآن، أحدهما مبدأ لاعقلي وهو أن كل شيء ممكن، ما يؤدي إلى أن تستبيح الآلة كل شيء في الإنسان. وثانيهما مبدأ لا أخلاقي وهو أن كل ما كان ممكناً، وجب صنعه، مما يؤدي إلى التحلل من كل الموانع الأخلاقية الضامنة للمكارم،. ولما كانت المناهج التقنية تتجه إلى رفع كل الضوابط الموجهة للسلوك، وإلى السقوط في الظلمات، فلايمكن اعتبا مهمة تحرير الإنسان وإسعاده مقصداً حقيقياً وفعلياً للممارسة العقلية العلمية الحديثة.

أما الوصف الثالث فهو الفوضوية، فإذا كان من المقاصد النافعة كذلك أن يؤدي المنهج العلمي إلى النظام والترتيب والوصل؛ فإن النظر في تاريخ العلم يبين أن النظريات العلمية، لانمو نمواً مطرداً، ولا يركب بعضها بعضاً ركوب الطبقات بعضها فوق بعض، متجهة خطوة خطوة إلى تققيق كمال المعرفة. وإنما هذه النظريات على الحقيقة بعضها قاطع عن بعض بكيث تقوم بينها علاقات تنافس وتباين وتمادم لا علاقة تكامل وتساند، مثال: (نظرية التكوين ونظرية التطور) ومثال: (نظرية الميكانيكا العقلية والميكانيكا الذرية) ومثال: (نظرية آينشتاين ونظرية نيوتن). أضف إلى كون هذه النظريات لا يكمل بعضها بعضاً، أن كلاً منها، ما أن يتخذ له طريقاً في الإجابة على بعض الأسئلة، حتى يقع في أسئلة أخرى قد تكون أعوص منها، فتأخذ الأسلة في التزايد والانتشار في كل ابتاه قد تؤدي إلى الخبط، فضلاً عن الأسئلة التي لا تلقى أبداً الإجابة داخل نطاق النظرية العلمية، سواء منها تلك التي تتصل بحدود الإطار النظري ووسائل التفسير به (نفسه)، أو تلك التي تتعلق بالخصائص الذاتية للأشياء أو بحقائقها. ولما 
كانت المناهج العقلية العلمية المتداولة، تؤدي إلى تضارب النظريات العلمية فيما بينها، فلايمكن التسليم بأن طلب النظام والتكامل يشكل مقصداً حقيقياً لمذه المنهاج.

وهكذا، يتضح بنا من النظر في مقاصد المنهج العقلي العلمي المشهور أن هذا المنهج قد يطلب النسبية والتفاضل بدل الوحدة والتكامل، ويطلب الاستحقاق بدل التحرير، ويطلب الفوضى بدل النظام.

وبهذا، بتحلب العقلانية العلمية المتداولة مقاصد غير نافعة، فتكون مخالفة لركن من أركان العقلانية السلمية، فهل توفّّ هذه العقلانية بشرط النجاعة في الوسائل؟

\section{المنهج العقلي العلمي وحدود النجاعة في الوسائل:}

إن من ينظر في سائل المنهج العقلي العلمي، يجدها هي الأخرى متصفة بأوصاف أربعة. الوصف الأول ادعاء تمام الموضوعية، فإن الممارسة العقلانية العلمية تدّعي تطهير وسائلها من كل أثر للمعاني والقيم الموجهة للحياة الإنسانية، بحجة التزام طريق "الموضوعية"، القائم -في نظرها- في الاقتصار على الاحتكام إلى الملاحظة الظاهرة والتجربة الحسية، حتى أصبحت المعاني الدينية والقيم الأخلاقية، تعد عندها بمنزلة عوائق وعقبات، تثبط العمل العلمي، وتخرجه عن حقيقته. والصواب أن تحصيل تمام الموضوعية غير ممكن، وكل ما تفعله هذه الممارسة العقلانية، هو أها تستبدل بلمعاني الدينية والقيم الأخلاقية، معاني وقيم أخرى غير دينية وغير أخلاقية.

ولما كان العلم المنقول إلينا مبنياً على هذا التصور الخناص للمعرفة الموضوعية (الذي يحسن بنا أن تطلق عليه اسم "الموضوعاوية")، فقد فاته تحصيل الوسيلة الناجعة في خدمة حياة الإنسان؛ لأن هذه الوسيلة تقتضي الجمع بين طلب المعرفة العلمية، والتزام المعاني والقيم الروحية والأخلاقية.

الوصف الثاني هو الجمود على الظاهر، فإن المنهج العقلي العلمي يجعل من موضوعاته -أياً كانت- مجرد ظواهر تقبل التحليل والتجريب. ولايخفى ما في النزعة في تصريف الأشياء إلى ظواهر من أسباب الوقوع في الخطأ، كأن نماثل بين الشيء وبين مظاهره، كما لو ماثلنا بين الرصيد من الذهب والأوراق النقدية التي نتداولها، وكأن نصرف تصريفاً ظاهرياً، أموراً لا تقبل هذا التصريف، كما لو مثّلنا على حقيقة القصد والنية بسهم مرسوم. 
ولما كان المنهج العقلي العلمي يكتفي بالظواهر، من دون الحقائق التي تستند إليها هذه الظواهر، فقد حرمت وسائل من النجاعة؛ لأن هذه النجاعة تستلزم الجمع بين ظواهر الأشياء وبواطنها.

والوصف الثالث هو الجمود على المكان والزمان؛ إذ لا يتم للشيء في نظر العلم الحديث كمال ظهوره-أي تحوله إلى ظواهر - إلا بإدخاله في حيز مكاني وزماني؛ لأن من شأن هذا التحييز، أن يمكن من إجراء وسائل التقدير والتقسيم والتركيب عليه، ولا تخفى الآثار السيئة لمذا التحييز، الذي يجعل ما هو غير ممتد متداً، وما هو غير قابل للمقدار قابلاً له، كأن يسوّي بين معنى التوجه في الصلاة، وبين الذبذبات الحاصلة في منطقة من مناطق الدماغ. ولما كان المنهج العقلي يحيز كمل شيء، فقد فاتته الإحاطة بالتوجهات والتطلعات إلى عالم المعاني السامية التي يتصف بها الإنسان الحي، وبذلك حرم أصلاً من أصول النجاعة المشروطة في العقلانية السليمة.

أما الوصف الرابع فهو اتخاذ الوسائط المادية، فإن العلم الحاصل بالمنهج العقلي المثداول، ليس مستفاداً بصورة مباشرة بانقداحه في قلب الإنسان، وإنما هو مستفاد من اصطناع الوسائط ووسائط الوسائط، ووسائط أخرى فوقها، حتى يتهيأ له ضبط الظواهر، وصفاً وبجريباً ومراقبة وتنبؤاً.

ويحكم هذا الطريق في اتخذا الوسائط، المبدأ الذي مقتضاه أنه: "كلما كان الشيء دقيقاً ولطيفاً في ظهوره، تعددت وتعقدت الوسائط إليه"، وعلى العكس من ذلك، "كلما كان الشيء مجسماً وكثيفاً، قلت الوسائط إليه"، وتترتب على هذا المبدأ النتيجة التالية وهي: "إن إدراك الحقائق الروحية الموصوفة أصلاً بكوها لا متناهية في الدقة واللطافة، سوف يستلزم من الوسائط المادية ما لاحصر له".

وحيث أن المنهج العقلي العلمي لا يفارق التوسل بالوسائط المادية في كل شيء، فقد امتنع عليه إدراك ما لا يتأتى بطريق هذه الوسائط، كالمعاني الروحية وبالتالي فاتته النجاعة المطلوبة.

يتبين من النظر في وسائل المنهج العقلي العلمي، أن هذه الوسائل غير ناجعة بسبب ادعائها تماما الموضوعية، ووقوفها عند الظواهر، وجمودها على الزمان والمكان، واقتصارها على الأسباب المادية. وعليه تكون العقلانية الديكارتية بخروجها عن النفع في المقاصد، وعن النجاعة في الوسائل، قد أخلت بمعيار التكاملية على تقدير أغا وفت في حدود، بمعياري القيمية والفاعلية. 
ولما ثبت أن العقلانية الغربية بشقيها الأرسطي والديكارتي، إما أها تخل بمعايير العقلانية السليمة التي حددناها في ثلاثة: "معيار الفاعلية" و"معيار القيمية" و"معيار التكاملية"، وإما أهما تسيء استعمال هذه المعايير، جاز لنا أن نعدها مرتبة دنيا في العقلانية نسميها مرتبة "التجريد"، فالتجريد هو ما كان من العقلانية بجرداً من اليقين في نفع المقاصد، ومن اليقين في نجاعة الوسائل،ولا نستغرب إذ ذاك أن تنقلب بالضرر على الإنسان إن قليلاً أو كثيراً.فكيف إذاً الخروج من هذه العقلانية المعرضة لعدم النفع في المقاصد،ولعدم النجاعة في الوسائل؟

\section{تقويم العقلانية العلمية:}

نقول عن الخروج من هذه العقلانية المجردة، يتم عن طريق التوسل بالقيم العملية؛ لأنه بفضل العمل يتم تلقيح

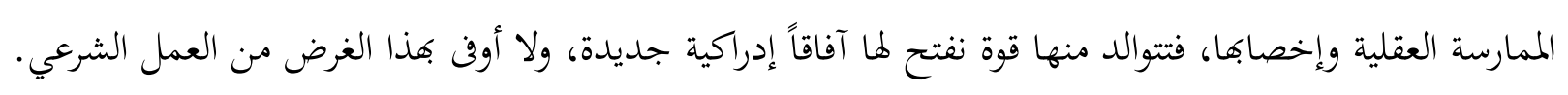

لكي نوضح كيف ان العمل بمد صاحبه بما يفتقده صحب العقل المجرد، فإننا نختاج إلى مزيد من التفصيل لمعياري القيمية والفاعلية، فهو ما ذكرنا من تعلق الأول بالمقاصد وتعلق الثاني بالوسائل. أما معيار القيمية، فإن لمان المقاصد التي هي مقتضاه تتصف بصفتين أساسيتين هما "الثبات" و"الشمول". أما صفة الثابت. فالمقاصد هي بمنزلة "معان" و "قيم" لا يستقيم لها التوجيه للسلوك والتأثير فيه، إلا إذا بقيت على حال الاستقرار وعلى حال الصدق. وأما صفة الشمول، فإن هذه المعاني لا تختلف باختلاف الأفراد، ولا يستقل بها الفرد عن غيره، وإنما يشترك أفراد الجماعة كلهم في الأخذ بها؛ والعمل وفقها.

وأما معيار الفاعلية، فان الوسائل التي هي مقتضاه تتصف بصفتين مقابلتين هما "التغير" و"الخصوص". أما صفة التغير، فإن الوسيلة التي هي بالذات، الفعل الذي يؤديه المرء لتقيق المقصد، لاتتخذ شكلاً واحداً عنده؛ وغنما تتخذ أشكالاً متعددة تنقلب مع تقلب ظروفه الحالية والمآلية فلو كان المقصد على سبيل المثال هو "حفظ الصحة"، فإن الوسيلة قد تكون هي فعل "تناول الدواء" وقد تكون هي مجرد "أكل الطعام" ود تكون هي "تناول طعام" معين يفضله المرء على غيره. وأما صفة الخصوص، فلما كانت الوسائل التي هي الأفعال تختلف باختلاف البواعث والظروف، فلاشيء أدل منها على خصوصية صاحبها، مما تلزم عنه أمور ثلاثة هي أن خصوصية المرء تزداد أو أو 
تنقص، بازدياد أو نقصان الأفعال التي يدخل فيها؛ وان الفعل المطلوب القيام به لايؤثر إلا بقدر استحكامه من هذه الخصوصية ومطابقته لمقتضى حالها؛ وأن التعرف على هذه الخصوصية يمكن من اختيار أنسب الأفعال وأبلغها في التأثير.

بفضل هاتين الدلالتين الجديدتين لكل ن معياري القيمية والفاعلية من جهة -دلالة الثبات والشمول في المقاصد بالنسبة لمعيار القيمية، ومن جهة ثانية دلالة التغير والخصوص، فبالوسائل النسبة لمعيار الفاعلية نستطيع أن نتبين الوجهين اللذين يمكن بكما العمل الشرعي، من ترك الاتصاف بالعقلانية المجردة، إلى طلب الاتصاف بعقلانية غير بجردة، وهما أن يكون الدخول في العمل الشرعي، بالقدر الذي يجصل للمكلف معه الاستعداد لإدراك ماهو متصف بالثبات والشمول، والتوسل إليه بما هو متصف بالتغير والخصوص.

وبجذا تنقسم العقلانية غير المجردة إلى قسمين: العقلانية غير الجمردة، القادرة على إدراك المعاني الثابتة والشاملة،

والعقلانية غير المجردة القادرة على الوسائل المتغيرة والخاصة. فلنبسط الكلام فيهما.

\section{العقلانية المسددة والمقاصد النافعة: - م}

بالنسبة لآثار تحصيل النفع في المقاصد، فإن من المعلوم أن المعاني الثابتة والشاملة (أو الكلية) التي تنبني عليها تكاليف الشريعة، هي التي اختصت بالذات باسم "المقاصد"، وقد أحصى منها علماء الشريعة صنوفاً بختلفة (ضرورية وحاجية وتكميلية) لا حاجة لنا هنا إلى ذكر تفاصيلها. ومعلوم أيضاً أن مقاصد الشرع هي أنفع المقاصد وأيقنها؛ لأغا لا تنعطف في عواقبها بالضرر، كما تنعطف به غيرها من المقاصد؛ ولن المكر الإلهي أو الاستدراج لا يجيء من جهتها، كما يجيء من جهة المقاصد غير الشرعية.

ولما كانت المقاصد الشرعية التي هي معان ثابتة وكلية، اجلب للنفع وأدفع للضرر من غيرها، لزم أن ينفتح للداخل في العمل الشرعي طريق إدراك المقاصد النافعة؛ لأن ها العمل يلقى في فهمه ما يبصره هذه القيم العليا. وبفضل هذا الإدراك، يكون الداخل في العمل الشرعي، قد جاوز مرتبة التجريد التي لا تُصصّل من المقاصد، إلا ما كان غير مأمون الجانب، ولا سليم العواقب، ونز في مرتبة تعلوها عقلانية وتفضلها رجاحة، نسميها بمرتبة "التسديد" 
فالعقل المسَدَّد هو إن العقل الذي اهتدى إلى معرفة المقاصد النافعة. وبهذا يكون العقل المستَّدّد قد استوفى الشرط المنصوص عليه في معيار القيمية، من معايير العقلانية الثلاثة السالفة الذكر، لكن على استيفائه لهذا الشرط لا يمكن الاعتبار هذذا العقل، حتى ننظر كيف هو عند استيفاء الشرط المنصوص عليه في معيار الفاعلية، المتعلق بالوسائل وهو شرط التغير والخصوص.

لقد رأينا أن المقاصد معان ثابتة وعامة، وان الوسائل التي تتخذ لتحقيقها، والتي ي الأفعال متغيرة وخاصة، وما كانت المقاصد عامة والوسائل خاصة، لا يلزم من إدراك المقصد النافع إدراك الوسيلة الناجعة؛ لأن إدراك الأعم لا يستلزم إدراك الأخص.

لذا فإن الداخل في العمل الشرعي، وإن حصّل إدراك المقاصد النافعة، فقد لا يكصل إدراك الوسائل الناجعة، ومالم يحصل اليقين في نجاعة وسائله، فإنها تبقى معرضة لآفات مختلفة، نذك منها آفنين اثنتين هما: "النظاهر" و"آفة التقليد".

أما التظاهر، فهو عبارة عن وصف يقوم بالمشتغل، عندما يقع منه التفاوت بين واقع الاشتغال عنده وبين ظاهر القصد منه، كالتكلف الذي يقوم في إخراج الأعمال التي لا تطابق عنده واقع الاشتغال، عن قصد التقرب بها إلى الله قصد التقرب بها إلى الناس. والتزلف الذي هو إتيان أعمال تطابق واقع الاشتغال مع إشراك الناس بالله في قصد التقرب لها، وكالتصرف الذي هو إتيان أعمال مطابقة لواقع الاشتغال، مع إشراك النفس بالله في التقرب بها.

وأما التقليد، فهو العمل بقول الغير من دون تحصل دليل عملي يثبت فائدة هذا القول، ومن أصنافه، التقليد الآلي الذي هو العمل بقول الغير من غير تحصيل دليل نظري يبت صحة هذا القول، والتقليد النظري الذي هو العمل بقول الغير مع تحصيل دليل نظري لا عملي يصحح هذا القول، والتقليد العادي الذي هو العمل بقول الغير مع حصر الدلالة العملي لهذا القول في الحركات الظاهرة، سواء استند هذا العمل إلى دليل يصحح القول المعمول به أو لم يستند إلى دليل. 
لا سبيل للداخل في العمل الشرعي لتحصيل الوسائل الناجعة، وتحصيل اليقين فيها، إلا بالإتيان بنصيب من العمل يفوق النصيب الذي أتى به لتحصل القدرة على إدراك المقاصد النافعة، ولايفوقه إلا إذا استوفى شروطاً ثلاثة، أولها أن يستقيم له الجمع بين المقال والسلوك؛ فكل معرفة عقلية تبلغ مرتبة التأثير بالوسائل، لابد لها من أن تنتقل من مستوى التمييز المجرد إلى مستوى التخلف السلوكي، حتى ولو كانت علماً نظرياً أو آلياً، كاللغة والمنطق والحساب؛ لأن التخلف بها سبب في نفوذ المعاني والقيم إليها، هذا النفوذ الذي يقيها التذبذب والاختلال في السير إلى المقاصد

النافعة.

وثانيهما أن يتم له الجمع بن معرفة الموضوع المتعقل ومعرفة الله؛ فكل معرفة علمية موصوفة بالنجاعة في الوسائل، تكون مفتاحاً من مفاتيح الاهتداء إلى طريق الله، والزيادة في ها الاهتداء بقدر ما هي علم بالموضوع الذي تختص ببحثه والكشف عن قوانينه، إذ الموجودات بجلى قدرته ومظهر صنعه، وكل من سرَّح فيها فكره، ممن استقام له تأثير الوسائل وجب أن يدركه فيها.

أما الشرط الثالث فهو أن يكون في اشتغاله العلمي متسع للاستزادة الدائمة، من غير خروج إلى ما فيه احتمال الضرر؛ فكل معرفة عقلية بالغة درجة التأثير بالوسائل، تكون مفتوحة الآفاق ومتسعة الرحاب، بحيث لا يخشى على الزيادة فيها، وعلى دوام هذه الزيادة من أن تحيد بها عن جادة المعقول، أو تسيء إلى المشتغل بوجه من الوجوه. فلما كانت هذه المعرفة قائمة على الاجتهاد في العمل والتحقق به، فليست تزداد بهذا الاجتهاد إلا تعلقاً بالقيم الموجهة وبالطرق النافذة إلى هذه القيم ورسوخاً في معرفة الله ومتى ازدادت تعلقاً ورسوخاً، ازداد أصحاهما إدراكاً للوسائل المؤثرة بحق.

وإذا استوف الداخل في العمل الشرعي هذه الشروط الثلاثة: أن لا ينفك قوله عن فعله، وأن لا تنفك زيادته عن فائدته، صارت أفعاله في تغيرها وخصوصيتها وسائل موصلة توصيلاً حقيقياً إلى المقاصد النافعة، أو قل صارت وسائل ناجعة.

ولهذا يكون هذا العاقل العامل، قد جاوز مرتبة التسديد التي لا تحصل إلا المقاصد النافعة، ونزل مرتبة تعلوها علانية نسميها مرتبة "التأييد" فالعقل المؤيّد هو إذاً، العقل الذي اهتدى إلى تحصل الوسائل الناجعة، فلاً عن تحصيل المقاصد النافعة. 
وحتى نستدل على رسوخ هذا العقل في العمل، هذا الرسوخ الذي مده بالنجاعة المطلوبة، ويزوده بالقدرة على التأثير نذكر الوجوه التي يحول بها العقل المؤيد تصورات العقل المجرد، وتمثلات العقل المسدد للشرع إلى معان عملية. أمّا بالنسبة لآثار تحصيل النجاعة في الوسائل، فمعلوم أن مُدْرَك العقل المجرد من الشرع عموماً، هو انه جملة من الحكام التي يقدر المكلف على تمييزها والتعرف عليها، كما يقدر المكلف على إنزاها على أفعاله، وواضح أن هذا التصور للشرع هو تصور نظري، فمعنيا "القدرة على التمييز" و "القدرة على الإنزال" يظلان معنيين نظريين يقفان عند حدود بيان استعدادات للمكلف. بينما في العقلانية المؤيدة يخزج معنى "القدرة على التمييز" إلى معنى عملي هو "قفل الخطاب" ويخرج معنى "القدرة على الإنزال" إلى معنى عملي آخر هو "تحمل الرؤية".

أما مقتضى تلقي الخطاب فهو أن المكلف يعلم أن الحق يخاطبه في كل شيء، وأن هذه المخاطبة مستمرة باستمرار حياته، وان نص هذا الخطاب، أن حفظ رسواً في الصحف المطهرة، فمعانيه مودعة فينفس المكلف، وفي الكون من حوله، وأن هذه الأكوان ما قامت ولا استقامت إلا بهذه المعاني الإلهية، التي على المكلف واجب طلبها، والتعرف عليها، والتقرب بها إلى الله.

وأما مقتضى تحمل الرؤية، فهو أن المكلف يعلم أن الله يراه رؤية لاتنقطع، وأن هذه الرؤية، إن جاءته بالرضى عن أفعاله، سعد سعادة لا يشقى بعدها، وإن جاءته بالسخط، شقي شقاوة لا يسعد بعدها، وبذلك فهو مطالب أن يراقب نفسه، ويراقب الله في كل أفعاله. ومعلوم أيضاً أن مدرك العقل المسدد من الشرع هو: أنه جملة من العبادات والمعاملات يُطالب المكلف بأدائها على شروطها بالقدر المستطاع، باعتبار أن هذه الطاعات ترجع في أصلها إلى المحافظة على مصالحه المادية والمعنوية.

فواضح أن هذا التصور للشرع، وإن فضل نتصور العقل المجرد بخروجه عن وصف النظر، فإنه مرتبة المقصد من العمل، فمعنى "الطاعة في العبادة" ومعنى "الطاعة في المعاملة"، معنيان يقفان عند حدود بيان المقاصد منهما. بينما في العقلانية المؤيدة يخرج معنى الطاعة في العبادة إلى معنى "الاشتغال بالله" ومعنى الطاعة في المعاملة إلى معنى "التعامل في الله"وكلاهما معنى عملي بتريبي صريح. 
أما مقتضى الاشتغال بالله فهو أن المكلف يدرك انه مخلوق للاشتغال بالله، وأن الاشتغال بغيره ينبغي أن يُذَكّره بالله دائماً وأبداً، فما يعقل المكلف شيئاً، إلا ويجعله هذا الشيء يعقل أمر ربه فيه.

وأما مقتضى التعامل في الله، فهو أن المكلف يأتي أعمالاً لصالحه يبنيها على اعتقاداته مقراً لغيره في ذات الوقت بكق الإتيان بمثل هذه الأعمال لصالحه، وبحق توجيهـا بما عنده من اعتقادات، كما يرتب المكلف هذه الأعمال جميعها بحسب ما يقتضيه الصالح الهام، باعتبار أن طلب هذا الصالح المشترك مفضٍ إلى مزيد الاشتغال بالله. ونشير همذا الصدد إلى أن قول الفقهاء المشهور: "ليس في الشريعة تكليف ينافي العقل أو لايمكن تعقله" الذي يُقصد به تبرير دخول المكلف تحت حكم الشريعة، لا يستقيم إلا في حدود التعريف الذي وضعناه للعقل المؤيد. العقل الذي لا يعارض الشرع، ليس هو العقل الذي ترىى في كنف المناهج العقلانية المجردة ذات الأصل اليوناني الغربي، وتشكل بأشكال مادية بحتة، صارفاً كل أثر للمعاني الغيبية، والقيم الأخلاقية. ولاهو العقل المسدد لأن هذا العقل لا ينجو من الاختلال على مستوى الوسائل، وإن أصاب على مستوى المقاصد، وإنما هو العقل المؤيد بالشروط التي ذكرناها من قبل في اجتماع القول والفعل، واجتماع المعرفة العلمية، والمعرفة الغيبية، وفي سلامة الزيادة في العمل. وعلى معنى العقل المؤيد، ينبغي أيضاً حمل الألفاظ القرآنية (يعقل) و(تعقلون) و(يعقلون) ونسوق على ذلك

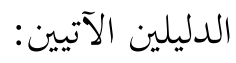

الدليل الأول أن هذه الألفاظ تأتي في معرض الكلام عن المغيبات والمكتّمات من أمور الغيب، ومعلوم أن العقل بالمعنى المجرد، محدود في إدراكه لقصوره عن النفع في المقاصد، وعن النجاعة في الوسائل، فلم يُجعل له سبيل لمعرفة المعاني الغيبة. كما أن العقل بالمعنى المسدد، وإن كان أقل محدودية في الإدراك من العقل المجرد، فلايبلغ درجة اليقين في الوسائل التي يستعملها، لذا لن يكون المقصود من الألفاظ القرآنية المذكورة إلا ما أسميناه بالعقل المؤيد، الذي يتوسل إلى المقصد المطلوب بالسبب المشروع. - مان.

والدليل الثاني أن هذه الألفاظ تجيء في القرآن مرادفة لكلمات (التذكير) و(التجبر) و(التبصر)، التي تدل بوضوح على معان لها تعلق بالمغيبات، وما يصدق عليها بالضرورة على لفظ (العقل) الذي هو مرادف لها. 
ويف الختام نجمل الكلام في ما سبق، فنقول بأن العقلانية بوجه عام عبارة عن ماهية الفعل الذي طلب صاحبه تحصيل مقاصد معينة بطرق وسائل معينة.

والعقلانية المجردة بوجه خاص، عبارة عن صفة الفعل الذي يطلب صاحبه تحصيل مقاصد، لا يقين في نفعها بطريق وسائل لا يقين في نجاعتها. وقدر رأينا أفها تُنخلُ بالنفع في المقاصد لوقوعها في النسبية والفوضى والاسترقاق، كما تخل النجاعة في الوسائل لإقصائها للمعاني الروحية، ووقوفها عند الظاهرة والجمود على الزمان والمكان، والأخذ بالوسائط المادية.

والعقلانية المسددة بوجه خاص، عبارة عن صفة الفعل الذي يطلب صاحبه تحصيل مقاصد نافعة، طريق وسال لا يقين في نجاعتها. وقد رأينا أها تقع في آنتي التظاهر والتقليد.

والعقلانية المؤيدة بوجه خاص، عبارة عن صفة الفعل الذي يطلب صاحبه تحصيل مقاصد نافعة، بطريق وسائل ناجعة. ولا يتم هذا الجمع بين نفع المقاصد في ثباما وشموليتها، وبين نجاعة الوسائل في تغيرها وخصوصيتها، إلا بدوام الاشتغال بالله وبلوغ الغاية فيه.

وما لم ننشئ منهجية عقلانية متصفة بأوصاف تحقق هذا الجمع، فلن يستقيم لنا بناء علم نظري أو طبيعي إسلامي ولا تشييد فكر إسلامي، علم وفكر نأتي فيهما بما لم يأت به غيرنا، ونصيب فيهما حيث لم يصب غيرنا. 